\title{
FUNCTIONAL EDIBLE COATINGS FOR DRIED GUAVA (Psidium guajava L.) SLICES
}

\author{
PUI KHOON HONG ${ }^{1 *}$, SHARMILAA SEVAN ${ }^{1}$ and NUR LIYANA MOHD IZAN ${ }^{2}$ \\ ${ }^{1}$ Faculty of Industrial Sciences and Technology, Universiti Malaysia Pahang, \\ Lebuhraya Tun Razak, 26300 Gambang, Kuantan, Pahang, Malaysia \\ ${ }^{2}$ Kuliyyah of Science, International Islamic University Malaysia, \\ Bandar Indera Mahkota, 25200 Kuantan, Pahang, Malaysia \\ *E-mail: hongp@ump.edu.my
}

Accepted 3 September 2020, Published online 25 October 2020

\begin{abstract}
Edible coating is an economical and effective approach towards maintaining the quality of minimally processed fruits, this concept was applied in the storage of dried guava slices. The objective of this study was to investigate the effectiveness of polysaccharide- and gelatin-based coatings in improving the storage quality of the dried guava slices. Sodium alginate (polysaccharide) and gelatin (protein) were used as the base for this model study, additives such as citric acid and fructooligosaccharide were added. Dried guava slices produced with different edible coatings were stored at 24 and $37.5^{\circ} \mathrm{C}$, the browning intensity, antioxidant stability and total plate count in the formulations were monitored for 8 weeks. Browning intensity in dried guava slices was less pronounced when citric acid and fructooligosaccharide were combined and incorporated into the sodium alginate- and gelatin-based formulations $(p<0.05)$. The same combination of ingredients helped in maintaining the antioxidant stability in the dried guava slices with gelatin-based coating. While presence of fructooligosaccharide in both of the sodium alginate- and gelatin-based formulations lowered the microbial load during the storage period $(p<0.05)$. These findings suggest a combination of citric acid and fructooligosaccharide could be an ingredient with multi-functional effects in preserving the quality of dried guava slices.
\end{abstract}

Key words: Guava (Psidium guajava L.), gelatin, alginate, edible coatings, functional

\section{INTRODUCTION}

Guava (Psidium guajava L.) is a tropical fruit commonly found in Malaysia. However, the fruit is perishable within days of post-harvest due to its high moisture content. Therefore, many preservation technologies are developed to extend the shelf-life and food safety of fruits. Drying is regarded as one of the most economical approaches in preserving fruits. The fruits are dehydrated or dried until a low moisture content is achieved. Although low moisture foods are shelf stable, the appearance (browning), microbiological stability and antioxidant quality remain a quality issue due to the susceptibility of the fruit exposed to long duration and high temperature during drying (Perera, 2005; Michalska et al., 2016; Udomkun et al., 2015).

Edible coatings or films are regarded as one of the economic methods to preserve fresh fruits. It is

* To whom correspondence should be addressed. a simple approach to maintain the quality of fruits at ambient temperatures. Edible coatings are commonly applied in minimally processed fresh fruits to provide a partial barrier to moisture loss, oxidation, volatile loss and prevent browning (Olivas \& Barbosa-Canovas, 2005). Generally, edible coatings can be divided into lipid-, resin-, polysaccharide- and protein-based. Gelatin is a protein obtained from hydrolysed collagen either from animal bone or skin. On the other hand, sodium alginate is a polysaccharide derived from brown seaweed.

To date, there is no report on the efficacy of the edible coatings applied on the storage quality of dried guava slices. In this study, sodium alginate (polysaccharide-based) and gelatin (protein-based) were chosen as candidates for this model study, they act as the base of the edible films due to their selective permeability towards exchange of $\mathrm{O}_{2}$ and $\mathrm{CO}_{2}$ (Linares-Morales et al., 2018). The aim of this study was to investigate the effectiveness of sodium 
alginate and gelatin coatings in improving the storage quality of the dried guava slices.

\section{MATERIALS AND METHODS}

\section{Materials}

Fresh matured guavas were peeled, deseeded and sliced at $1 \mathrm{~cm}$ thickness. The guava slices were blanched in distilled water at $100^{\circ} \mathrm{C}$ for $10 \mathrm{~min}$, drained and cooled to room temperature. Later, blanched fruits were soaked into sugar solution $(50 \% \mathrm{w} / \mathrm{v})$ for $18 \mathrm{hr}$ at $4^{\circ} \mathrm{C}$. The fruit slices were then dipped into coatings formulated with different combinations of bovine gelatin $(\mathrm{G})$, sodium alginate (A), fructooligosaccharide (F) and citric acid (C) (Table 1) for $30 \mathrm{~min}$ at $4-8^{\circ} \mathrm{C}$. Drying of fruit slices were carried out at $60^{\circ} \mathrm{C}$ for $10 \mathrm{~h}$. Samples were cooled to room temperature and dusted with icing sugar prior to storing. The fruit slices were sealed in polyethylene (PET) bags and stored at room temperature for further analyses.

For measurement of browning intensity, antioxidant and microbiological analyses, the dried fruits were stored at 24 and $37.5^{\circ} \mathrm{C}$ in order to mimic the storage conditions found in retail stores and conventional warehouses, they were sampled at every 2 weeks for a total duration of 8 weeks.

\section{Measurement of browning intensity}

Exactly $2 \mathrm{~g}$ of each of the dried fruits were homogenized in $20 \mathrm{~mL}$ distilled water using a rotorstator homogenizer (15000 rpm at $2 \mathrm{~min}$, Ultra Turrax T25, IKA, Malaysia). The mixture was centrifuged at $5000 \times \mathrm{g}$ for $10 \mathrm{~min}$ at $4^{\circ} \mathrm{C}$ (Universal Centrifuge 5911, Kubota, Japan). The supernatant was filtered and the aliquot was transferred into a cuvette to measure the absorbance at $420 \mathrm{~nm}$ (Liu et al., 2019). All measurements were performed in triplicates.

\section{Antioxidant activity stability}

The 2,2-diphenyl-1-picryl-hydrazyl-hydrate (DPPH) radical scavenging activity was carried out as according to Hong et al. (2014). The samples were prepared the same manner as described in the browning intensity measurement. The homogenized samples were centrifuged, filtered with Whatman No. 1 filter papers and diluted with distilled water. The percentage of DPPH scavenging activity was compared against a control (consisted of DPPH only) over the course of 8 weeks storage period using the equation below:

$\%$ DPPH Scavenging Activity $=\frac{\text { Control }- \text { Sample }}{\text { Control }} \times 100 \%$

\section{Microbiology analysis}

Samples collected every 2 weeks were tested in triplicate for total plate count. Exactly $2 \mathrm{~g}$ of each of the dried fruit sample were mixed with $18 \mathrm{~mL}$ of nutrient broth at the ratio of 1:9. The samples were homogenized and 10-fold serial dilutions were applied using the nutrient broth. About $0.1 \mathrm{~mL}$ of each of the diluted samples was spread onto nutrient agar plates and incubated at $37.5^{\circ} \mathrm{C}$ for $24 \mathrm{~h}$. The results were expressed as $\log \mathrm{cfu} / \mathrm{g}$ of dried fruits.

\section{Data statistical analysis}

All means obtained were analysed with one-way analysis of variance (ANOVA) and separated by Tukey test. The means were considered statistically significant when $p<0.05$.

\section{RESULTS AND DISCUSSION}

\section{Development of browning intensity}

Browning is a common occurrence observed in dehydrated fruits during storage. It is mainly attributed to Maillard reaction and oxidation (Bolin \& Steele, 1987; Li et al., 2019). Formation of brown pigments is related to the accumulation of Maillard reaction products such as melanoidins (Madrau et al., 2010). The formation of browning pigment during storage is shown in Figure 1. Lower storage temperature $\left(24^{\circ} \mathrm{C}\right)$ promoted formation of browning pigment in the samples whereas at a higher storage temperature $\left(37.5^{\circ} \mathrm{C}\right)$, formation of brown pigments in samples progressed at a slower pace. Throughout the entire storage period, the freshly dried guava slices without coating (control) and guavas with alginate based coating (A) were significantly darker compared to the other coatings $(p<0.05)$. In week 8 ,

Table 1. Formulation of coatings applied to guava slices

\begin{tabular}{lccccccc}
\hline & \multicolumn{7}{c}{ Formulation } \\
\cline { 2 - 8 } Ingredients, \% w/v & Control & G & GC & GCF & A & AC & ACF \\
\hline Gelatin (G) & - & 2.0 & 2.0 & 1.5 & - & - & - \\
Sodium alginate (A) & - & - & - & - & 2.0 & 2.0 & 1.5 \\
Citric acid (C) & - & - & 1.0 & 1.0 & - & 1.0 & 1.0 \\
Fructooligosaccharide (F) & - & - & - & 0.5 & - & - & 0.5 \\
\hline
\end{tabular}




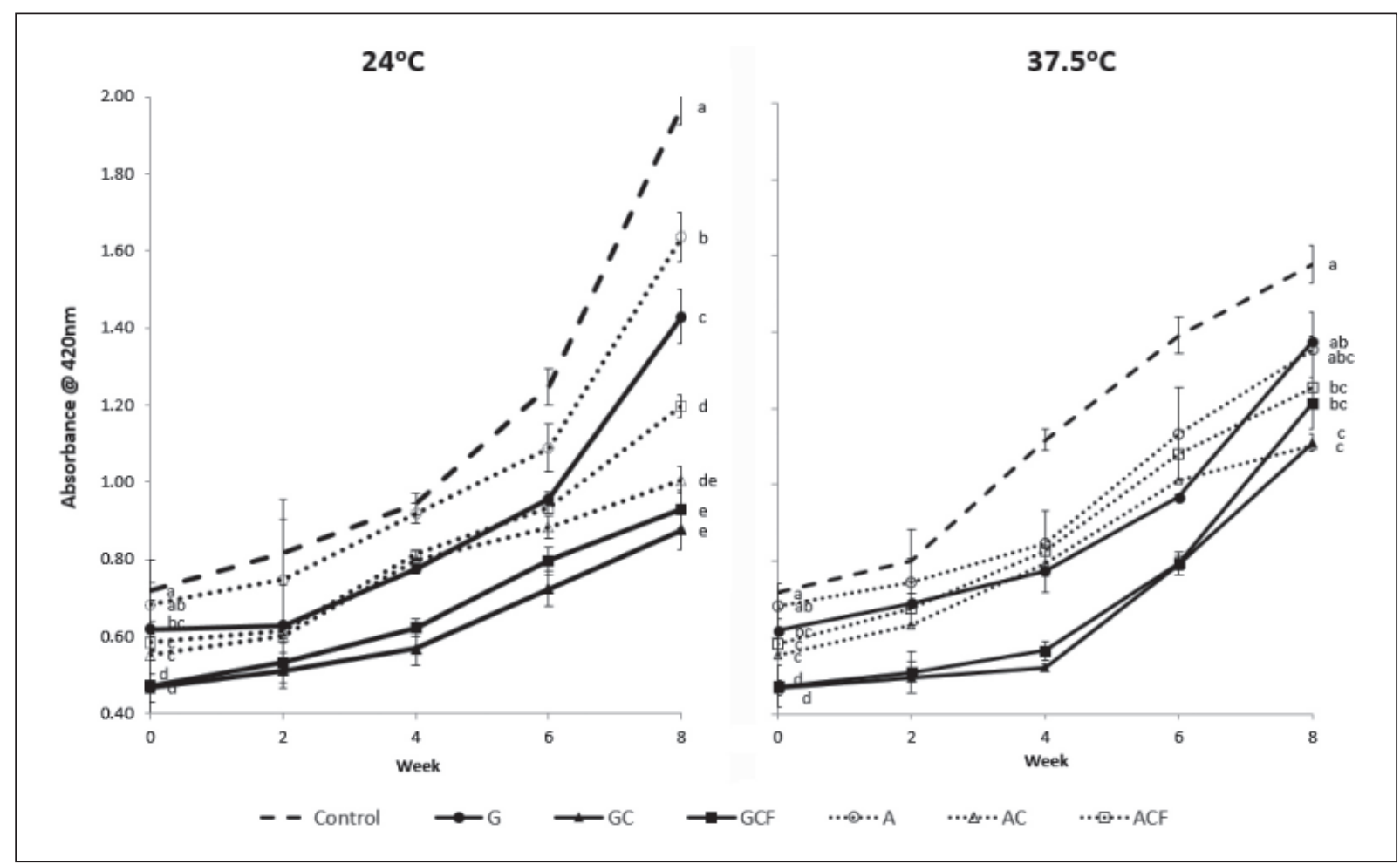

Fig. 1. Development of browning intensity in dried guava slices treated with edible coatings formulated with gelatin $(\mathrm{G})$, alginate (A), citric acid (C), fructooligosaccharide (F) during storage at 24 and $37.5^{\circ} \mathrm{C}$ for 8 weeks. Different letters within the same week indicate significant difference at $p<0.05$.

coatings containing citric acid ( $\mathrm{GC}$ and $\mathrm{AC}$ ) and fructooligosaccharide (GCF and $\mathrm{ACF}$ ) gave relatively lower browning intensity than the rest of the treatments $(p<0.05)$ regardless of storage temperature applied. This indicates that the presence of citric acid and fructooligosaccharide could suppress the formation of Maillard reaction products, whereby the presence of citric acid leads to a lower $\mathrm{pH}$ in the mixture. This is in agreement with a few studies which incorporated citric acid in reducing the occurrence of browning (Campos et al., 2016; Liu et al., 2019; Martins et al., 2000), this is because the Maillard reaction is more favoured at greater $\mathrm{pH}$ levels. On the other hand, chitosan oligosaccharide-soy protein isolate (SPI) conjugate produced milder browning in the Maillard reaction compared to glucose-SPI conjugate. The oligosaccharide-SPI conjugate produced greater amount of reactive fluorescent intermediates, which were less prone to form brown pigments (Xu et al., 2019). Similarly, the formation of browning pigment is relatively slower in Maillard reaction mixture containing oligosaccharide-amino acid-sulphite compared to the monosaccharide-amino acidsulphite models (Wedzicha \& Kedward, 1995). Thus, the presence of oligosaccharide in the coating formulations could reduce the brown pigments formation from the Maillard reaction.

\section{Stability of antioxidant activity}

The stability of the antioxidant activity in the coated guava slices was compared at 24 and $37.5^{\circ} \mathrm{C}$ for 8 weeks (Figure 2). Initially, the antioxidant capacity levels in samples with alginate based coating were similar to that of the control $(p>0.05)$. However, towards the end of the stability study (week 8), most of the coated samples (except for gelatin-citric acid (GC) coating stored at $24^{\circ} \mathrm{C}$ ) showed significant reduction in antioxidant activity $(p<0.05)$. In particular, the antioxidant activity in the alginate based coatings (A, AC, and $\mathrm{ACF}$ ) dropped steeply starting in week 6 , and it is more evident at higher storage temperature $\left(37.5^{\circ} \mathrm{C}\right)$ as the antioxidant activity in A, AC and ACF reduced to nearly half of the original capacity. On the other hand, the antioxidant activity measured in gelatin based coatings were relatively higher than those of alginate based during storage. This is in line with notion that the Maillard reaction products generated in the protein based (gelatin) coating during storage contributed to the antioxidant capacity (Hong et al., 2014; Kchaou et al., 2019). It is interesting to note that at $24^{\circ} \mathrm{C}$, the gelatin-citric acid coated (GC) guava showed similar levels of antioxidant activity as compared to the control during storage. However, the same formulation was less stable at higher storage temperature $\left(37.5^{\circ} \mathrm{C}\right)$ with approximately 


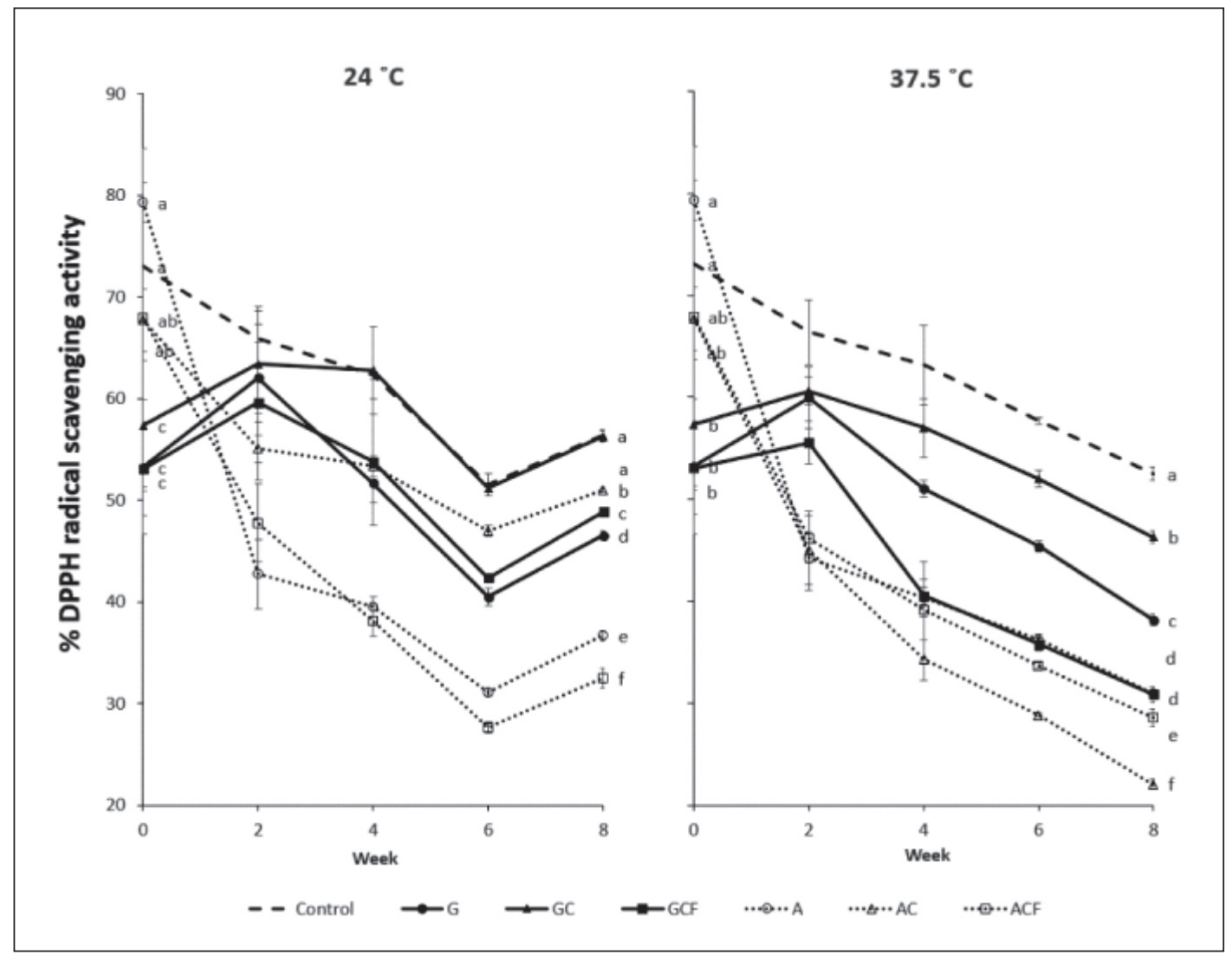

Fig. 2. Stability of antioxidant activity in dried guava slices treated with edible coatings formulated with gelatin $(\mathrm{G})$, alginate (A), citric acid (C), fructooligosaccharide (F) during storage at 24 and $37.5^{\circ} \mathrm{C}$ for 8 weeks. Different letters within the same week indicate significant difference at $p<0.05$.

$11 \%$ of total reduction in DPPH radical scavenging activity observed. The presence of citric acid in the coating formulation may provide a synergistic effect between the polyphenolic compounds, which could act as a potent chelating agent (Baldwin et al., 1995).

\section{Microbiological analysis: total plate count}

The viable microbe load was monitored at 24 and $37.5^{\circ} \mathrm{C}$ in every 2 weeks (Figure 3). Samples incubated at $24^{\circ} \mathrm{C}$ showed a gradual increment in the microbial load over the course of 8 weeks. However, the total plate count in all treatments was significantly lower than that of control $(p<0.05)$, particularly in GCF, which resulted a reduction of about $1.5 \log \mathrm{cfu} / \mathrm{g}$ in microbial load. At $37.5^{\circ} \mathrm{C}$, most of the treatments showed similar growth trend compared to control at week 8 , except for both GCF and ACF which were significantly lower $(p<0.05)$ than the rest of the samples. This suggests that there is a synergistic interaction between a combination of fructooligosaccharide and citric acid, either in the polysaccharide (alginate) or protein based (gelatin) coating that retards microbial growth in the dried fruits. Further investigation is needed to understand the mechanism of the interaction.

\section{CONCLUSION}

In this study, the effect of different formulations and storage temperature on the storage quality of dried guava slices was investigated. The presence of citric acid and fructooligosaccharide in both sodium alginate- and gelatin-based formulations was able to suppress the browning development in dried guava slices. Moreover, the addition of citric acid and fructooligosaccharide in the gelatin-based coating maintained the antioxidant stability when stored at $24^{\circ} \mathrm{C}$, however this effect was not observed in other formulations at higher storage temperatures. On the other hand, incorporating fructooligosaccharide into the coating formulations helped in lowering the microbial load throughout the storage period. These findings suggest a combination of citric acid and fructooligosaccharide in the edible coating could produce multi-functional effects (corresponding to anti-browning, antioxidant and antimicrobial 


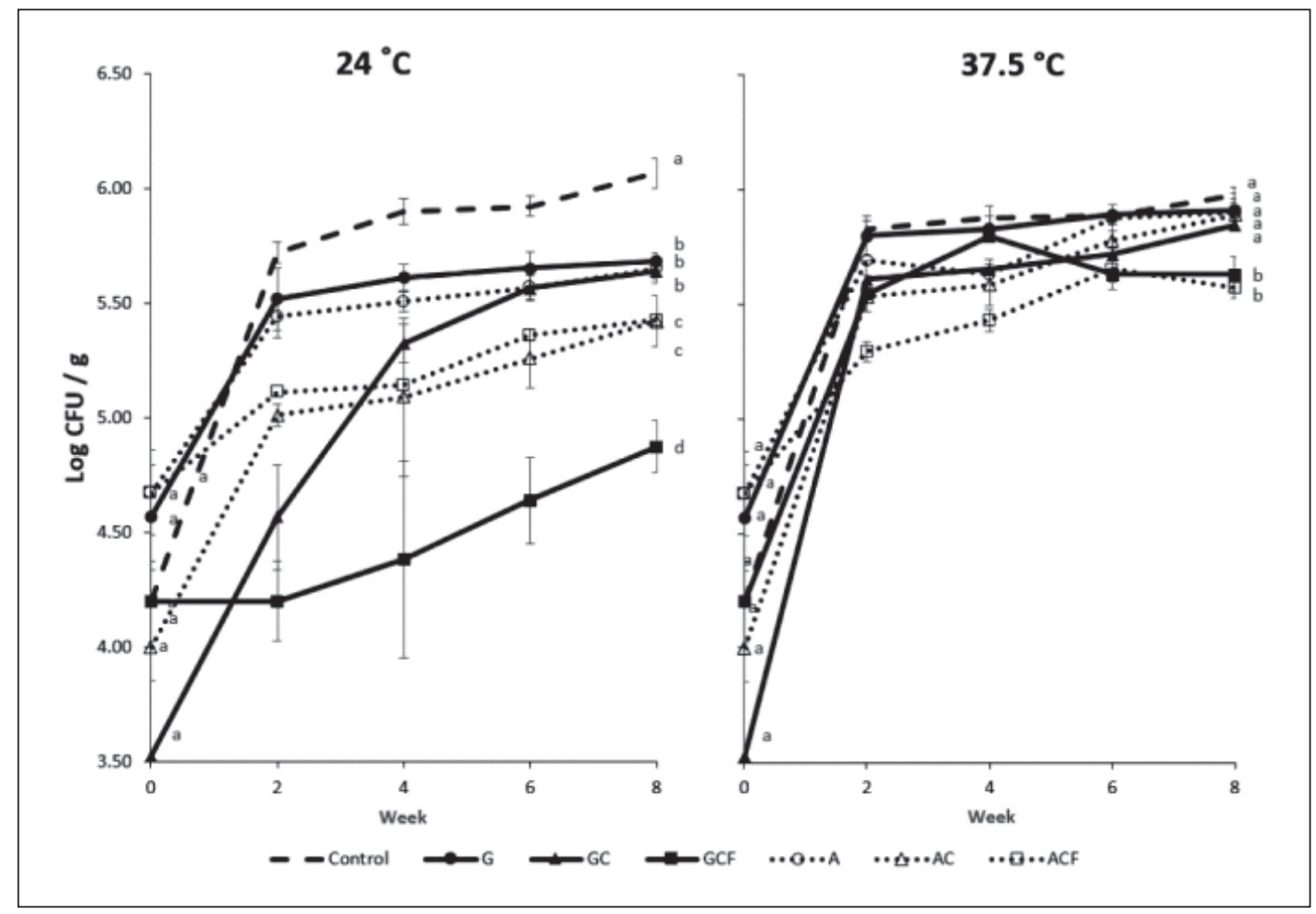

Fig. 3. Microbial load in dried guava slices treated with edible coatings formulated with gelatin $(\mathrm{G})$, alginate (A), citric acid (C), fructooligosaccharide (F) during storage at 24 and $37.5^{\circ} \mathrm{C}$ for 8 weeks. Different letters within the same week indicate significant difference at $p<0.05$.

activity) in the preservation of dried guava slices. Further investigation is needed to understand the mechanisms between these ingredients.

\section{ACKNOWLEDGEMENTS}

The authors would like to acknowledge the Universiti Malaysia Pahang (UMP) for financial support provided under the UMP Internal Grant RDU 1703197. Authors would also like to thank Kia Shing Importers \& Exporters Sdn. Bhd. for supplying fresh guavas in this study.

\section{REFERENCES}

Baldwin, E., Nisperos-Carriedo, M.O. \& Baker, R.A. 1995. Edible coatings for lighly processed fruits and vegetables. HortScience, 30(1): 35-38.

Bolin, H.R. \& Steele, R.J. 1987. Nonenzymatic browning in dried apples during storage. Journal of Food Science, 52(6): 1654-1657.

Campos, D., Aguilar-Galvez, A. \& Pedreschi, R. 2016. Stability of fructooligosaccharides, sugars and colour of yacon (Smallanthus sonchifolius) roots during blanching and drying. International Journal of Food Science and Technology, 51(5): 1177-1185.
Hong, P.K., Gottardi, D., Ndagijimana, M. \& Betti, M. 2014. Glycation and transglutaminase mediated glycosylation of fish gelatin peptides with glucosamine enhance bioactivity. Food Chemistry, 142: 285-293.

Kchaou, H., Benbettaieb, N., Jridi, M., Nasri, M. \& Debeaufort, F. 2019. Influence of Maillard reaction and temperature on functional, structure and bioactive properties of fish gelatin films. Food Hydrocolloids, 97: 105196.

Li, X., Wu, X., Bi, J., Liu, X., Li, X. \& Guo, C. 2019. Polyphenols accumulation effects on surface color variation in apple slices hot air drying process. LWT - Food Sceince and Technology, 108: 421-428.

Liu, P., Lu, X., Li, N., Zheng, Z. \& Qiao, X. 2019. Characterization, variables, and antioxidant activity of the Maillard Reaction in a fructosehistidine model system. Molecules, 24: 56.

Linares-Morales, J.R., Gutierrez-Mendez, N., RiveraChavira, B.E., Perez-Vega, S.B. \& NevarezMoorillon, V. 2018. Biocontrol processes in fruits and fresh produce, the use of lactic acid bacteria as a sustainable option. Frontiers in Sustainable Food Systems, 2(50).

Madrau, M.S., Sanguinetti, A.M., Del Caro, A., Fadda, C. \& Piga, A. 2010. Contribution of melanoidins to the antioxidant activity of prunes. Jounral of Food Quality, 33: 155-170. 
Martins, S.I.F.S., Jongen, W.M.F. \& van Boekel, M.A.J.S. 2000. A review of Maillard reaction in food and implications to kinetic modelling. Trends in Food Science and Technology, 11: 364-373.

Michalska, A., Wojdylo, A., Lech, K., Lysiak, G.P. \& Figiel, A. 2016. Physicochemical properties of whole fruit plum powders obtained using different drying technologies. Food Chemistry, 207: 223-232.

Olivas, G.I. \& Barbosa-Canovas, G.V. 2005. Edible coatings for fresh-cut fruits. Critical Reviews in Food Science and Nutrition, 45(7/8): 657-670.

Perera, C. 2005. Selected quality attributes of dried foods. Drying Technology, 23(4): 717-730.
Udomkun, P., Nagle, M., Mahayothee, B., Nohr, D., Koza, A. \& Muller, J. 2015. Influence of air drying properties on non-enzymatic browning, major bio-active compounds and antioxidant capacity of osmotically pretreated papaya. $L W T$ - Food Sceince and Technology, 60(2): 914922.

Wedzicha, B.L. \& Kedward, C. 1995. Kinetics of the oligosaccharide-glycine-sulphite: reactionship to the browning of oligosacchatide mixtures. Food Chemistry, 54(4): 397-402.

Xu, Z., Huang, G., Xu, T., Liu, L. \& Xiao, J. 2019. Comparative study on the Maillard reaction of chitosan oligosaccharide and glucose with soybean protein isolate. International Journal of Biological Macromolecules, 131: 601-607. 